\title{
Echocardiographic diagnosis of isolated pulmonary valve endocarditis
}

\author{
BRUNILDE DANDER, BRUNO RIGHETTI, ARRIGO POPPI \\ From the Cardiology Department, Ospedale Civile Verona, Italy
}

SUMMARY A patient is described in whom diagnosis of isolated pulmonary valve endocarditis was made by $M$-mode and two dimensional echocardiography. Angiography confirmed the presence of vegetations on the pulmonary valve. At cardiac surgery a quadricuspid, non-stenotic valve withĩ ruptured medial leaflet covered by necrotic vegetations and a small ventricular septal defect were ${ }^{\infty}$ found.

Echocardiography is known to be useful in diagnosing valvular endocarditis ${ }^{12}$ of the mitral and aortic valves but only two cases of pulmonary valve endocarditis have been previously diagnosed in this way. We report another.

\section{Case report}

A 46-year-old man, known to have an undiagnosed asymptomatic congenital heart defect, had a high temperature in November 1979. He was treated with antibiotics which were at first effective but pyrexia reappeared two weeks later. Cephalosporin was given intravenously for 10 days, but the patient became very weak, and haemorrhagic purpura appeared on the legs; evening pyrexia persisted. Finally, in May 1980, he was admitted to this hospital; bacterial endocarditis was suspected and penicillin started.

At physical examination the patient appeared very ill and febrile, with gross hepatosplenomegaly. A grade 4/6 harsh pansystolic murmur was heard in the second and the third left intercostal space followed by a grade $1 / 6$ diastolic murmur. The second heart sound was almost inaudible on the pulmonary area.

The electrocardiogram and chest $x$-ray film appeared to be within normal limits. The M-mode echocardiogram (Fig. 1) showed multiple dense echoes on the posterior leaflet of the pulmonary valve, which showed abnormal movement. The two dimensional echocardiographic examination $\left(30^{\circ}\right.$ sector scan) (Fig. 2) showed large polypoid vegetations freely moving with the cardiac cycle between the outflow tract of the right ventricle and the main pulmonary artery. Repeated blood cultures grew Staphylococcus cutis.
Treatment with cefuroxime led to a brief remission $\overrightarrow{0}$ of fever with apparent clinical improvement but high fever reappeared after 10 days despite continuous treatment and finally the patient developed a lefto lower lobe infarction with pleural effusion. As he was so ill, cardiac catheterisation and angiocardiography, previously planned, were abandoned and cardiaco surgery was performed on the evidence of the $e^{\circ}$ echocardiographic diagnosis on 5 June. The pulmo-을 nary artery was incised transversely above the level of the valve. A quadricuspid non-stenotic valve was seen; the medial leaflet was ruptured and covered by an overgrowth of necrotic tissue (Fig. 3); a small ven- $-\overrightarrow{\mathrm{C}}$ tricular septal defect was found just below the pulmo-䍐 nary valve which was excised. A biological prosthesisowas inserted, and the ventricular septal defect sutured 3 . with four stitches on Teflon pledgets.

Culture of the valve grew Staphylococcus cutis.

\section{Comment}

Right sided endocarditis, particularly of the pulmonary valve, is rare. While the tricuspid valve is fre-o quently infected in narcotic addicts, pulmonary valves involvement was described in only two of $127 \operatorname{such}_{\mathrm{E}}^{N}$ cases $^{3-6}$ and never as an isolated finding.

Isolated pulmonary valvar infection is indeed exceptional. Of 149 cases of infective endocarditis in children reported by Johnson et al., ${ }^{7}$ there was only? one case, in a patient with severe pulmonary stenosis. 0

Only two cases of pulmonary valve endocarditiso diagnosed by means of echocardiography have been reported. The first, described by Kramer et al. in $1977,{ }^{8}$ occurred in a young heroin addict with multio valvular involvement. The second was reported in 


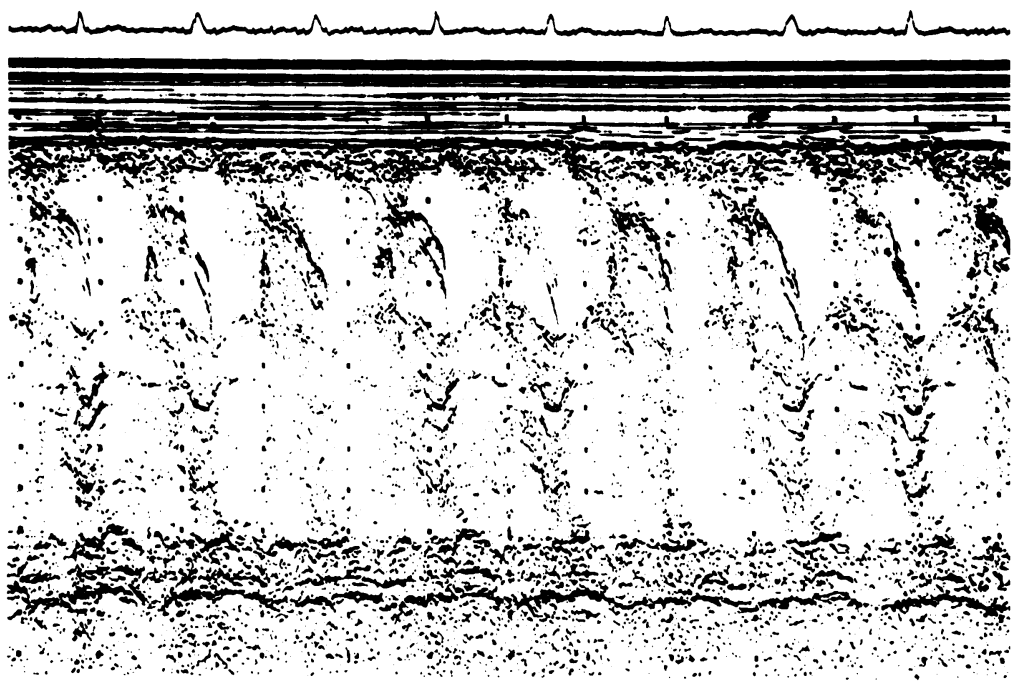

Fig. 1 M-mode echocardiogram showing multiple, dense, shaggy echoes on the pulmonary valve.

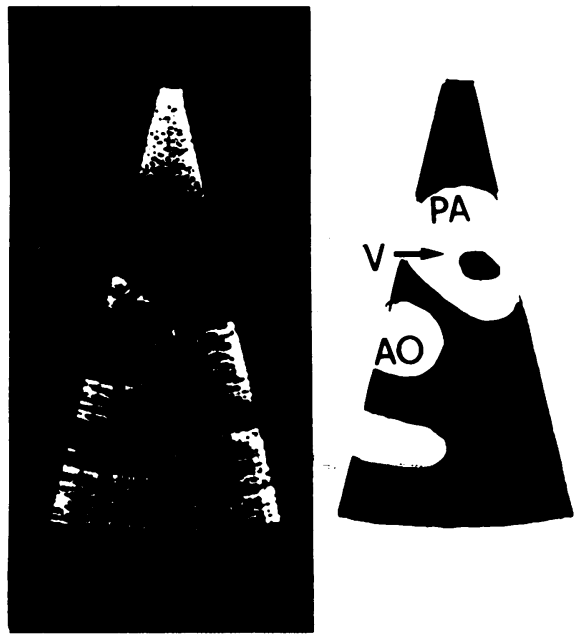

Fig. 2 Cross-sectional echocardiogram in the short axis view, illustrating a large mass $(V)$ on the pulmonary valve consistent with a vegetation. PA, pulmonary artery; $A O$, aorta; $V$, vegetation.

1979 by Dzindzio et al. ${ }^{9}$; the organism was the gonococcus which was though to have a particular affinity for the pulmonary valve.

Our patient was not a narcotic addict, and did not have a gonococcal infection or pulmonary valve stenosis. Echocardiography was diagnostic, indicating which valve had vegetations. M-mode echocardiography showed these as shaggy, irregular large echoes on the medial leaflet of the pulmonary valve, and the two dimensional technique gave precise information about their size and mobility.

On the basis of these findings it was thought that endocarditis had occurred on a mild congenital pulmonary valve stenosis. At surgery, however, a small ventricular septal defect was found with a malformed but non-stenotic pulmonary valve. We suggest that 


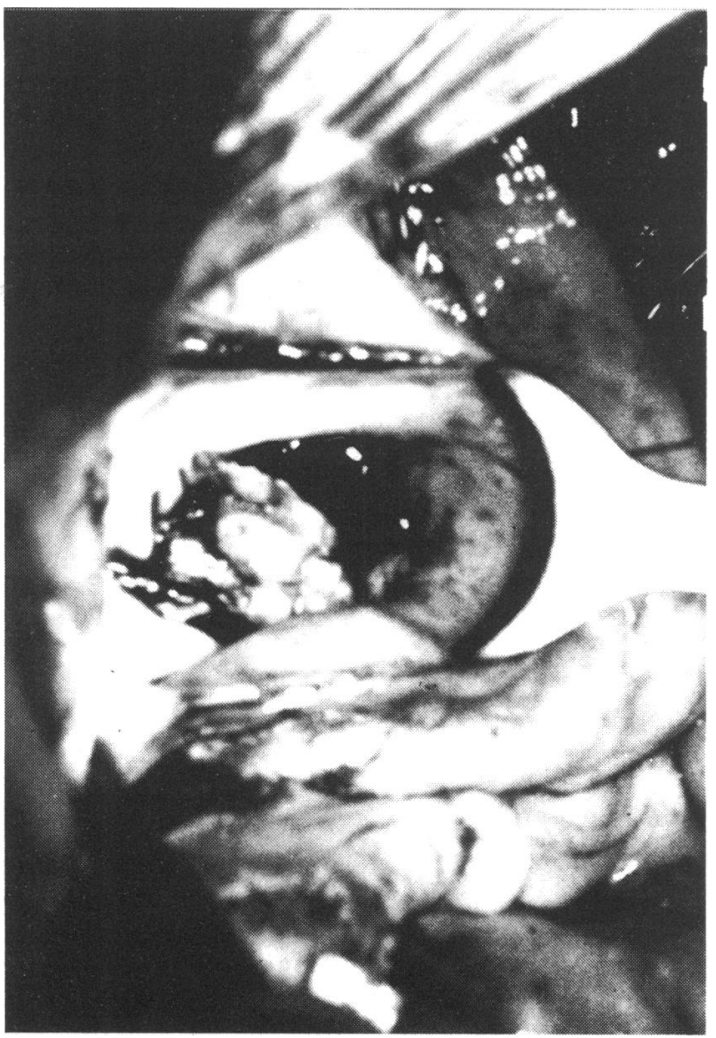

Fig. 3 The pulmonary valve at surgery seen from above: on the anteromedial aspect there is a large polypoid endocarditic vegetation.

the ventricular septal defect may have produced a jet lesion on the pulmonary valve that predisposed to infection.

The clinical course of this patient, with the poor response to medical treatment and the complication of pulmonary embolisation, made surgery the best fornt. of treatment for this particular case.

The authors wish to acknowledge the help in the studf and treatment of this case given by Drs $R$ Albier (surgical intervention) and $\mathrm{C}$ Buonanno (angiographiक study).

\section{References}

1 Wann LS, Dillon JC, Weyman AE, Feigenbaum He山 Echocardiography in bacterial endocarditis. $N$ Engl $\frac{\text { P }}{\rho}$ Med 1976; 295: 135-9.

2 Wann LS, Hallam CC, Dillon JC, Weyman AE, Feigen baum $\mathrm{H}$. Comparison of $\mathrm{M}$-mode and cross-sectionat echocardiography in infective endocarditis. Circulation 1979; 60: 728-33.

3 Cherubin CE, Baden M, Kavaler F, Lerner S, Cline WO Infective endocarditis in narcotic addicts. Ann Intern Med 1969; 69: 1091-8.

4 Banks T, Fletcher R, Ali N. Infective endocarditis i heroin addicts. Am f Med 1973; 55: 444-51.

5 Dreyer NP, Fields BN. Heroin-associated infective. endocarditis: a report of 28 cases. Ann Intern Med 1973:

6 Graham DY, Reul GJ, Martin R, Morton J, Kennedg $\mathrm{JH}$. Infective endocarditis in drug addicts: experiences with medical and surgical treatment. Circulation 1973\% 48, suppl III: $37-41$.

7 Johnson DH, Rosenthal A, Nadas AS. A forty-yea review of bacterial endocarditis in infancy and childhood? Circulation 1975; 51: 581-8.

8 Kramer NE, Gill SS, Patel R, Towne WD. Pulmonary valve vegetations detected with echocardiography. $A m \mathcal{F}$ Cardiol 1977; 39: 1064-7.

9 Dzindzio B, Meyer LR, Osterholm R, Hopeman A Woltjen J, Forker AD. Isolated gonococcal pulmonar valve endocarditis: diagnosis by echocardiography. $\mathrm{Cir} \stackrel{?}{?}$ culation 1979; 59: 1319-24.

Requests for reprints to Dr B Dander, Divisione Caro diologica, Ospedale Civile di Borgo Trento, $3710 \bar{Q}$ Verona, Italy. 